\title{
THE CATALYTIC OXIDATION OF ORGANIC CONTAMINANTS IN A PACKED BED REACTOR
}

\author{
L. VAN DE BELD, M. P. G. BIJL, A. REINDERS, B. VAN DER WERF and \\ K. R. WESTERTERP* \\ Chemical Reaction Engineering Laboratories, Department of Chemical Engineering, University of \\ Twente, PO Box 217, NL-7500AE Enschede, The Netherlands
}

(Received 24 May 1994; accepted for publication 12 September 1994)

\begin{abstract}
The catalytic oxidation of several hydrocarbons was studied over noble metal and metal oxide catalysts. A fast empirical method was developed to determine the minimum operating temperature required to guarantee complete conversion of the hydrocarbon.

The influence of the operating parameters such as the inlet concentration and residence time, as well as the chemical character of the component to be oxidized, have been investigated. The results can be described satisfactorily by a simple isothermal, plug flow reactor model and first-order reaction kinetics. In the case of simultaneous oxidation of different components a significant mixture effecl was not observed. The presence of water in the feed did significantly inhibil the oxidalion of alkanes.

Of the applied catalysts. Pt was the most effective for the combustion of the alkenes, whereas $\mathrm{Pd}$ showed a higher activity for the oxidation of alkanes.
\end{abstract}

\section{INTRODUCTION}

In recent years a lot of attention has been paid to processes for environmental protection. To control air pollution, catalytic combustion can be applied to destruct polluting volatile organic compounds (VOCs); see, e.g. Prasad et al. (1984) and Zwinkels et al. (1993). Comparing catalytic combustion to thermal combustion, heterogeneous catalysed reactions usually proceed at much lower temperatures. During the last decade, several research groups have studied the influence of the operating conditions on the performance of catalytic combustors; see, e.g. Hermia and Vigneron (1993), Mazzarino and Barresi (1993) and Noordally et al. (1993). Tichenor and Palazzolo (1987) studied the catalytic oxidation of single components and their mixtures; they made a ranking of destructibility of the contaminants depending on their nature. Barresi et al. (1992) showed that in the case of aromatic hydrocarbons, the reaction rate of one component will be influenced by the presence of another aromatic specie.

Also, a large research effor is being put into the improvement of the catalyst. Most commonly, noble metal catalysts like palladium or platinum are used because they exhibit a high specific activity. Hiam et al. (1968) and Schwartz et al. (1971) studied the oxidation of several hydrocarbons on a pure platinum or palladium wire; normally, however, the noble metal will be deposited on a ceramic support such as $\mathrm{Al}_{2} \mathrm{O}_{3}$. Different support materials and structures have been tried in order to improve the catalyst performance; see Baldwin and Burch (1990a,b), Hicks et al. (1990a,b)

*To whom correspondence should be addressed. and Najbar ef al. (1993). Also, more recently, mixed oxides have been used as a catalyst; for these catalysts higher reaction temperatures have to be employed, but under lean conditions they probably give lower $\mathrm{NO}_{x}-$ formation from nitrogen bound fuels and they are less expensive. Taskina et al. (1993) studied the oxidation of some organic compounds over a $\mathrm{Al}-\mathrm{Fe}$ oxide catalyst, Kuznetsova et al. (1993) applied a chromium catalyst, and Agarwal and Spivey (1992) used a $\mathrm{MnO}_{2}-\mathrm{CuO}$ catalyst.

In air purification processes, high conversions of the VOCs are required and low exit concentrations have to be guaranteed. Chemical reactions are very sensitive to reaction temperature and thus the performance of catalytic converters can be controlled by this temperature; the optimum value is determined by parameters like the residence time, the component to be burned and the catalyst used. A change in one of these factors will also cause a change in the optimum operating temperature.

The catalytic oxidation of VOCs was studied in a packed bed reactor. In this paper, a fast method developed by the authors to determine the minimum reaction temperature, $T_{99}$, will be discussed, which should be applied in the converter to obtain $99 \%$ conversion of the contaminants. The influence of residence time, the water content in the feed, the chemical character of the organic component and the effect of adding other compounds were studied. The performance of different catalysts and support materials were compared. The kinetic parameters, i.e. the activation energy and the pre-exponential factor were estimated by fitting the experimental results to a mathematical model. 


\section{THEORY}

The complete oxidation of organic components in a catalytic packed bed reactor was studied. If the conversion of a contaminant is followed as a function of the catalyst temperature, an S-curve of the conversion vs the reaction temperature is to be expected. The exact shape of this curve depends on the kinetics of the reactions, the mass transport, and the operating conditions of the reactor. If this curve can be described well, a tool will have been obtained to determine the minimum reaction temperature for a $99 \%$ conversion of a compound at the specified flow rate. Of course, the minimum reaction temperature, $T_{99}$, can be determined directly from the experimental results. By fitting these results to a reactor model, numerical values for the kinetic parameters can be obtained. The main assumptions made in order to derive the model equations are:

- Conditions in the reactor bed are isothermal, i.e. there are neither radial nor axial temperature gradients.

- The gas is in plug flow, and it behaves ideally.

- The temperature dependence of the reactions can be described by an Arrhenius expression.

- The reactions are of the first order with respect to the hydrocarbon; oxygen is in such large excess it does not influence the reaction rates. For all experiments the oxygen partial pressure was kept constant.

- The mass capacity of the catalyst can be neglected and the development of the concentration profiles is instantaneous; adsorption phenomena do not play an important role.

- Interparticle mass transport limitations can be neglected.

The model comprises a mass balance for each component:

$$
0=-u_{g} \frac{\mathrm{d} C_{j}}{\mathrm{~d} z}-R_{j}
$$

using the following definitions:

$R_{j}=k_{r} P_{j}=k_{x} \mathrm{e}^{E_{\mathrm{uci}, J} / R T} P_{j}$

$$
\begin{gathered}
C_{j}=\frac{P_{j}}{R T} \\
\tau=\frac{L}{u_{g}}
\end{gathered}
$$$$
u_{g}=u_{g 0} \frac{T}{T_{0}}
$$

With $T_{0}$ being the temperature at reference conditions, substituting these expressions into eq. (1) and integrating, yields:

$$
\ln \left(1-\xi_{j}\right)+-R T_{0} \tau_{0} k_{x} \mathrm{e}^{-E_{u<1, j} / R T}
$$

and for a required conversion of $99 \%$, eq. (2) can be rewritten as:

$$
T_{99}=\frac{E_{\text {aci }}}{R} \frac{1}{\ln \left(0.217 k_{x} R T_{0} \tau_{0}\right)} .
$$

Experimentally, the outlet concentration of the hydrocarbon is measured as a function of the temperature in the catalyst bed. The calculated conversion is fitted to eq. (2) to produce numerical values of the activation energy, $E_{j}$, and the preexponential factor, $k_{x}$. Both a linear and a non-linear regression method have been used; see Wentworth (1965a,b) and Press et al. (1989). According to Chen and Aris (1992), better results will be obtained if a non-linear method is applied to determine the Arrhenius constants.

The reactor was assumed to operate isothermally; in reality, axial and radial temperature gradients will occur. At different axial and radial positions the temperature is measured in the reactor. The mean temperature, $\bar{T}$, can be calculated as the number average or, because a higher temperature has a larger impact on the obtained conversion, probably it is better to calculate $\bar{T}$ based on mean reaction rates, thus:

$$
\begin{aligned}
& \bar{T}=\frac{1}{N} \Sigma T_{i} \\
& \bar{T}=-\frac{E_{\text {act }}}{R}-\frac{1}{\ln \left(\frac{1}{N} \Sigma \exp \left(-E_{\mathrm{acl}} / \mathrm{RT}_{\mathrm{i}}\right)\right)} .
\end{aligned}
$$

For the latter expression, a value of the activation energy and, therefore, an additional iteration step is required to find the kinetic parameters. In the authors' experience, errors caused by either different fit methods or different ways of averaging the temperatures, normally give only small differences in the results. In Fig. I, a graphical representation of the fit procedure is depicted for a typical experiment.

\section{EXPERIMENTAL SETUP}

In Fig. 2, a schematic drawing of the experimental installation is shown. The reactor had an inner diameter of $0.038 \mathrm{~m}$, a length of $0.40 \mathrm{~m}$ and was made of stainless steel. The reactor was surnounded by an electrical oven of $3 \mathrm{~kW}$. A frame was placed in the reactor on which the thermocouples were fixed. The bed temperature was measured at ten different

$$
\begin{aligned}
\xi & =\frac{P_{j, \text { in }}-P_{j, \text { oul }}}{P_{j, \text { in }}} \\
\tau_{0} & =\frac{L}{u_{g} 0} .
\end{aligned}
$$

positions with $0.5 \mathrm{~mm}$ K-type thermocouples. Because of the external heating, radial gradients are always present in the reactor, so the temperature was measured at several radial as well as different axial positions. The maximum length of the catalyst bed was $0.2 \mathrm{~m}$; for most experiments a bed length of $0.1 \mathrm{~m}$ was used.

Air, to which the gaseous contaminants were added, was fed into the reactor. The air flow and the concentrations of the combustibles were set by means of Brooks thermal mass flow controllers. Also, part of the air stream could be saturated with methanol by 


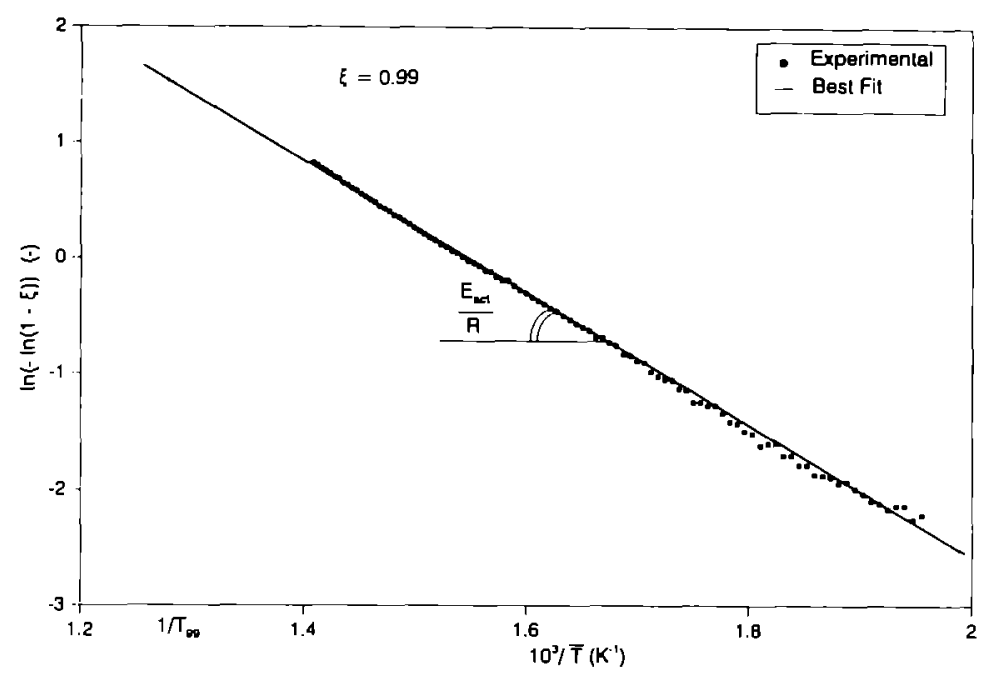

Fig. I. Schematic representation of the fit method used. $C_{0 \text {,propanc }}=0.087 \mathrm{vol} \%$; $u_{R 0}=0.19 \mathrm{~m} / \mathrm{s} ; L=0.20 \mathrm{~m}$; Catalyst I, see Table 2.

leading it through a methanol container kept at approximately $35^{\circ} \mathrm{C}$ and cooling down the outcoming stream to $25^{\circ} \mathrm{C}$ in a partial condenser. This ensured complete saturation of the air stream and the methanol concentration could be varied by changing the air flow. The influence of water on the process could be studied by adding water to the air stream in a similar system. In case of emergency, or to purge the system, nitrogen could be fed into the reactor.

The hydrocarbon concentrations in the inlet and outlet streams were measured on-line with a FIDanalyser supplied by JUM Engineering. During the process, $\mathrm{CO}_{2}$ was produced and, therefore, the $\mathrm{CO}_{2}$ concentration was also measured continuously with a Maihak-610 $\mathrm{CO}_{2}$-infrared analyser. Measuring both the reactant and the product gives the opportunity to check the mass balance. The water concentration in the inlet stream was determined with a chilled mirror dewpoint hygrometer made by Panametrics.

An experiment was carried out as follows: the air flow and the hydrocarbon concentrations were set and then the inlet concentrations of the hydrocarbons (HC) and $\mathrm{CO}_{2}$ were measured. An experiment was started by switching a three-way valve so the sample for analysis was taken from the reactor outlet and the reactor was heated up to $600^{\circ} \mathrm{C}$ with a mean heatingup rate of $5-30^{\circ} \mathrm{C} / \mathrm{min}$. Every $10 \mathrm{~s}$, temperatures and concentrations were measured and all data were collected by a Data Acquisition Control Unit (DACU) of Hewlett Packard and sent to a HP computer.

\section{RESULTS AND DISCUSSION}

The operating parameters investigated are listed in Table 1. To activate and stabilize a fresh catalyst, it was kept for several hours at $550-600^{\circ} \mathrm{C}$ under reaction conditions. For a $\mathrm{Pd} / \mathrm{Al}_{2} \mathrm{O}_{3}$ catalyst, several authors found an increase in activity with time-onstream; see, e.g. Baldwin and Burch (1990a), Briot and Primet (199l) and Garbowski et al. (1994). Most of the catalysts used showed both a positive and negative change in activity during the first hours of operation.

In deriving the model equations, isothermal cunditions were assumed; in a fast dynamic method it is not possible to satisfy this condition completely. Depending on the heating-up rate and the gas velocity, radial and axial temperature gradients of $10-40$ and $25-50^{\circ} \mathrm{C}$, respectively, were observed. Normally, a heating-up rate of $15^{\circ} \mathrm{C} / \mathrm{min}$ was applied and an experiment lasted about $30 \mathrm{~min}$. Before an experiment was started, the reactor was preheated to approximately $130-160^{\circ} \mathrm{C}$ to be sure that adsorption phenomena do not influence the results.

\section{Mass balance}

In Fig. 3, the hydrocarbon and $\mathrm{CO}_{2}$ concentrations as well as the mean temperature are given as a function of time. If at every moment during the experiment the overall mass balance is satisfied, the sum of the $\mathrm{HC}$ and $\mathrm{CO}_{2}$ concentrations, that is the total carbon concentration, should remain constant as a function of time. In Fig. 3 it is shown that after the reaction starts at $t \sim 1000 \mathrm{~s}$, the sum of these concentrations in the outlet decreases. At higher temperatures of approximately $360^{\circ} \mathrm{C}$, the total carbon concentration in the outlet becomes higher than in the inlet. Integration of the sum over time shows that the overall mass balance is satisfied. The higher value of the sum at the end of the experiment

Table 1. Range of operating conditions in the experimental installation

\begin{tabular}{lcl}
\hline Gas velocity & $0.1-0.5$ & $\mathrm{~m} / \mathrm{s}$ \\
Reactor length & $0.1-0.2$ & $\mathrm{~m}$ \\
Residence time & $0.4-1.6$ & $\mathrm{~s}$ \\
Inlet concentration of hydrocarbons & $0.2-3$ & $\mathrm{~g} \mathrm{C} / \mathrm{m}^{3}$ \\
Heating-up rate & $5-30$ & ${ }^{\circ} \mathrm{C} / \mathrm{min}$ \\
\hline
\end{tabular}




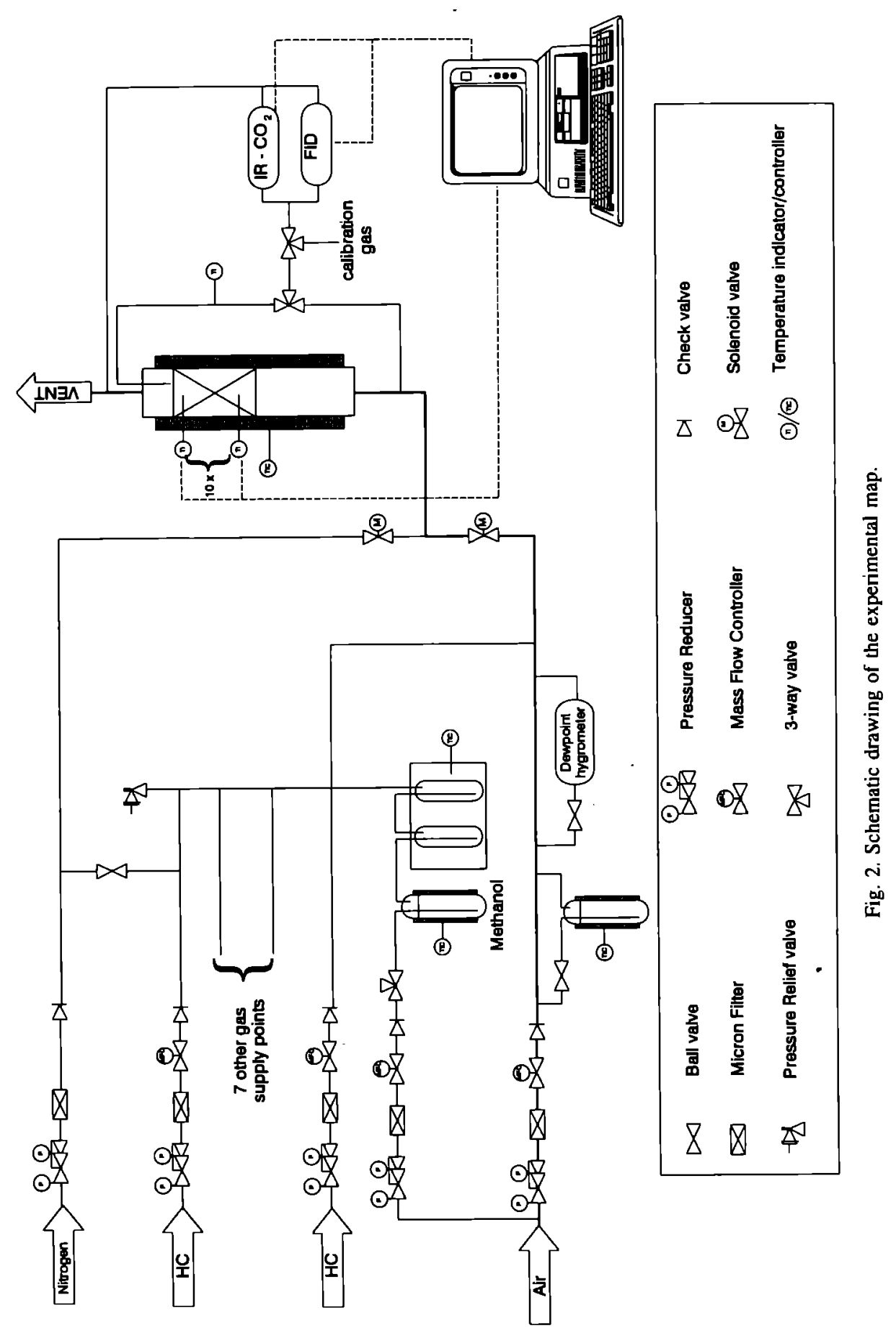




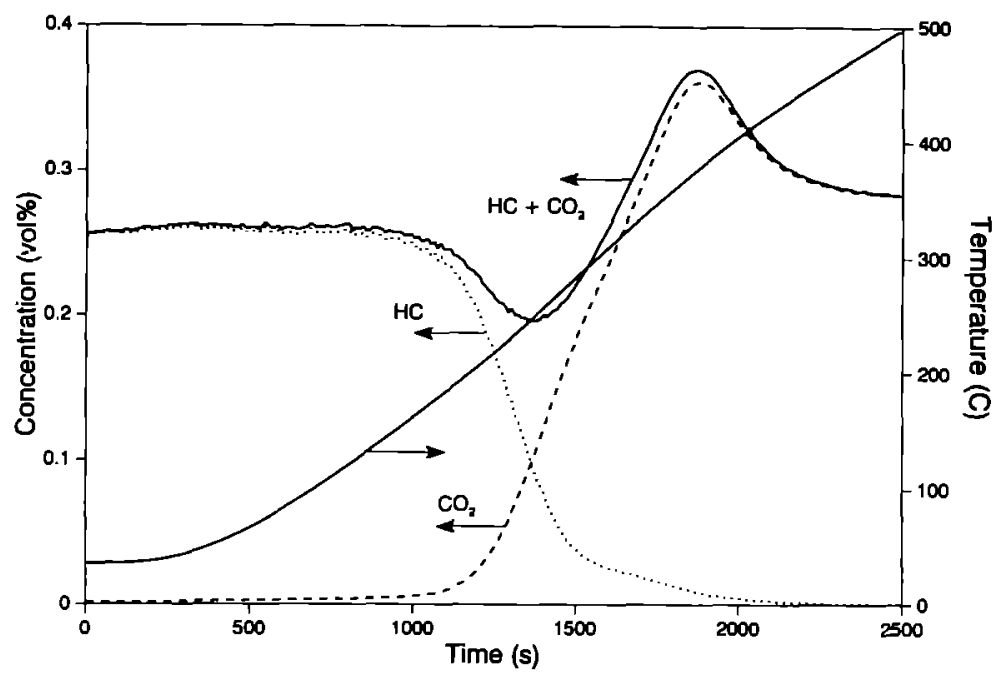

Fig. 3. The $\mathrm{CO}_{2}$, ethene $(0.5 \times \mathrm{HC})$ and total carbon $\left(=\mathrm{CO}_{2}+\mathrm{HC}\right)$ concentration in the reactor outlet and the bed temperature as a function of time. $u_{g 0}=0.21 \mathrm{~m} / \mathrm{s}$; $L=0.20 \mathrm{~m} ; C_{0, \text { ethene }}=0.12$ vol\%; Catalyst $\mathrm{I}$, see Table 2 .

is caused by the fact that the FID is calibrated for methane, whereas the sensitivity of the FID for ethene is lower. Different experiments have been carried out to explain these phenomena with the following results.

- With gas chromatographic analysis, no components in the reactor outlet stream could be detected other than reactants and $\mathrm{CO}_{2}$.

- Adsorption and desorption measurements have been carried out with $\mathrm{CO}_{2}$ and ethene, in air as well as in nitrogen. At low temperatures both ethene and $\mathrm{CO}_{2}$ absorb, but also both components desorb at temperatures below $130^{\circ} \mathrm{C}$. At higher temperatures no desorption peaks were observed.

- The only way to succeed in reproducing the peak at $360^{\circ} \mathrm{C}$ was to start an experiment for carrying out a reaction, heat up to $300^{\circ} \mathrm{C}$, cool down the reactor and heat up again without reaction. At approximately $360^{\circ} \mathrm{C}$, with both air and nitrogen, a significant increase was found in $\mathrm{CO}_{2}$ concentration, and also a small amount of a hydrocarbon could be detected in the reactor outlet.

Probably, this effect originates from the alumina support. Boreskov (1966) reported on the formation of hydroxyl groups on the alumina which at higher temperatures are removed again from the surface in the form of water. Mulcahy et al. (1993) found strong chemisorption of $\mathrm{CO}_{2}$ on alumina; they stated that $\mathrm{CO}_{2}$ primarily adsorbs at the hydroxyl groups. So probably $\mathrm{CO}_{2}$ is released together with water from the surface, causing an increase of the $\mathrm{CO}_{2}$ concentration in the outlet. Infrared analysis of the catalyst surface showed a carbonate compound was formed on that surface and also small amounts of $\mathrm{CH}_{2}$ and $\mathrm{CH}_{3}$ - could be detected. From a theoretical point of view, the carbonate can also be formed on PdO; an attempt to determine this failed, because the Pd concentration was too low. Under reaction conditions at $300^{\circ} \mathrm{C}$, the catalyst is dark coloured; at higher temperatures the catalyst regains its original yellow/ brown colour. A similar change in colour was observed by Frusteri et al. (1993) and explained by a reoxidation of metallic $\mathrm{Pd}$.

\section{Comparison to steady-state measurements}

From the foregoing experiences, it is evident that making use of a dynamic method can have a rather large impact on the results obtained. From Fig. 3 it was concluded that the $\mathrm{CO}_{2}$-concentration-time relation cannot be used due to strong adsorption of $\mathrm{CO}_{2}$. Also, some organic material is detected on the

Table 2. Properties of the catalysts and support materials

\begin{tabular}{lccc}
\hline No. & BET-surface $\left(\mathrm{m}^{2} / \mathrm{g}\right)$ & Support material & Active component \\
\hline I & 192 & $\mathrm{Al}_{2} \mathrm{O}_{3}$ & $0.07 \mathrm{wt} \% \mathrm{Pd}$ \\
II & 322 & $\mathrm{Al}_{2} \mathrm{O}_{3}$ & $0.41 \mathrm{wt} \% \mathrm{Pd}$ \\
III & 133 & $\mathrm{Al}_{2} \mathrm{O}_{3}$ & $0.06 \mathrm{wt} \% \mathrm{Pt}$ \\
IV & 59 & $\mathrm{TiO}_{2}$ & $0.11 \mathrm{wt} \% \mathrm{Pt}$ \\
V & 209 & $\mathrm{Al}_{2} \mathrm{O}_{3}$ & $9.5 \mathrm{wt} \% \mathrm{Cu} / 8.6 \mathrm{wt} \% \mathrm{Mn}$ \\
VI & 101 & $\gamma-\mathrm{Al}_{2} \mathrm{O}_{3}$ & - \\
VII & 6 & $\alpha-\mathrm{Al}_{2} \mathrm{O}_{3}$ & - \\
\hline
\end{tabular}




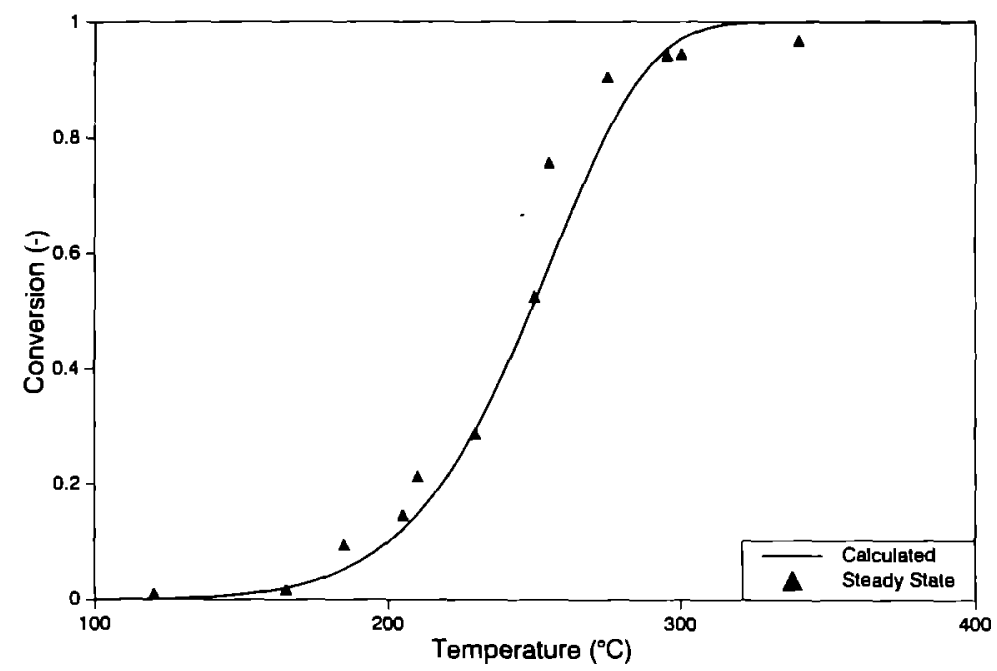

Fig. 4. Conversion of ethene as a function of the reactor temperature. Comparison of steady-state measurements to a profile calculated with the use of kinetic parameters obtained from a dynamic experiment. $C_{0, \text { ethene }}=0.275$ vol\%; $u_{g 0}=$ $0.26 \mathrm{~m} / \mathrm{s} ; L=0.20 \mathrm{~m} ;$ Catalyst I, see Table 2 .

surface. Steady-state measurements were compared with dynamic experiments. The steady-state measurements were carried out in the same equipment; about 30 to $40 \mathrm{~min}$ were required to attain the steady state. In Fig. 4, a conversion-temperature relation calculated with data from a dynamic experiment is compared to steady-state results. Over the whole temperature-conversion field the agreement is acceptable, although at higher conversions it becomes less so. This may probably be caused by desorption of organic components in the reactor and the piping, resulting in some delay of the measured decrease in HC concentration. The deviations occur in the steepest part of the curve and where small errors in the measured mean temperature result in rather large errors in the conversion. Despite this, the HCconcentration-temperature relation can be measured accurately enough to determine the minimum reaction temperatures for complete conversion.

\section{Influence of inlet concentration}

First-order reaction kinetics were assumed with respect to the hydrocarbon. This means that $T_{99}$ is insensitive to a change inlet concentration. In Fig. 5, $T_{99}$ is plotted as a function of the inlet concentrations of ethene and ethane, respectively. For both components, $T_{99}$ increases with increasing inlet concentration; this suggests a reaction order lower than one. In all cases shown in Fig. 5, the reaction started at nearly the same initial temperature. Ribeiro et al. (1994) found a strong inhibition by the reaction products, $\mathrm{H}_{2} \mathrm{O}$ and $\mathrm{CO}_{2}$, on the oxidation of methane on a Pd catalyst. For higher inlet concentrations, the amount of reaction products is increased and the reaction is

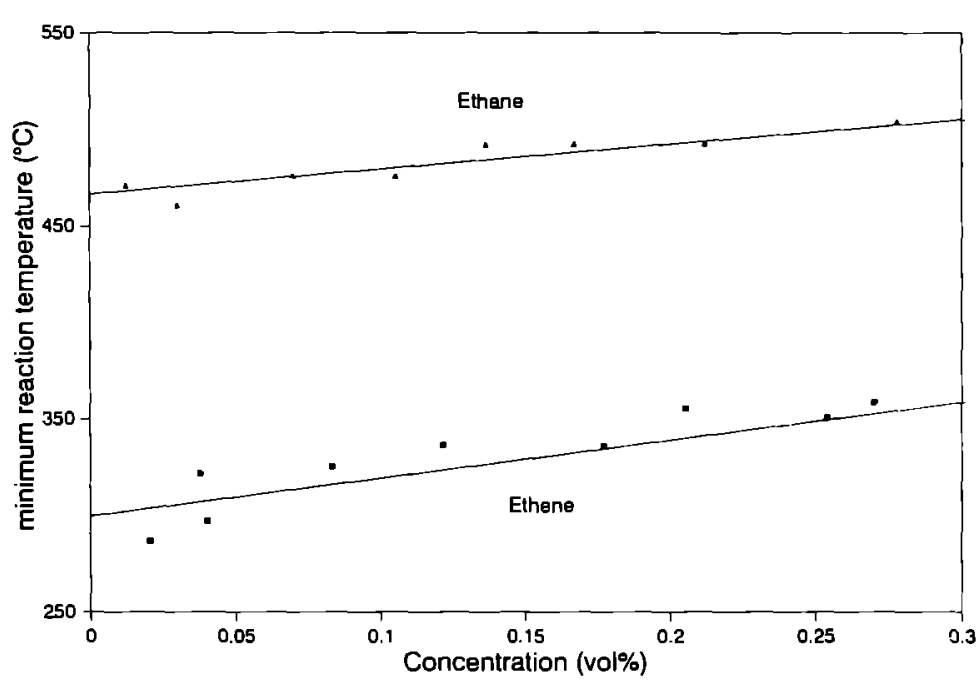

Fig. 5. Influence of the inlet concentration on the minimum reaction temperature for both ethene and ethane, $u_{x 0}=0.20 \mathrm{~m} / \mathrm{s} ; L=0.20 \mathrm{~m}$; Catalyst 1 , see Table 2. 


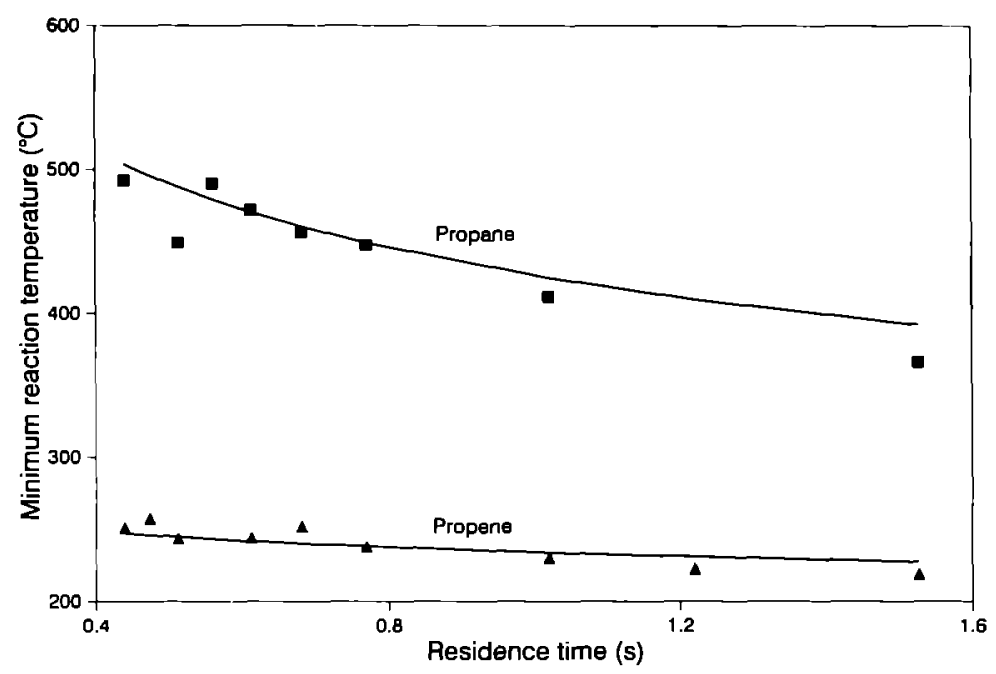

Fig. 6. Influence of the residence time on the minimum reaction temperature of propane and propene. Lines are calculated using the model; for kinetic parameters see Table 3. $C_{0}=0.085$ vol\%; Catalyst I, see Table 2 .

more inhibited for the same conversion. So the value of $T_{99}$ will increase with higher inlet concentrations. High inlet concentrations also cause relatively large heat effects and consequently the temperature gradients change. The mean temperature is possibly overestimated. Furthermore, at low inlet concentrations the experimental error becomes rather large.

\section{Influence of the residence time}

In Fig. 6, $T_{99}$ is plotted as a function of the residence time for both propane and propene. Increasing residence times results in decreasing $T_{99}$ values. Shorter residence times have to be compensated for by higher temperatures. As the dependence of the reaction rate on temperature is very strong, a large change in residence time requires only a small change in temperature. The reaction rate of propane is less sensitive to temperature than that of propene. The solid lines in Fig. 6 were calculated by making use of eq. (3); for the kinetic parameters required in the calculations, the mean values of all experiments were used; see also Table 3 . Evidently the model is able to predict the experiments rather well; the deviations are caused mainly by a large error in the pre-exponential factor and by experimental uncertainties.

\section{The chemical character of the combustible}

In air purification processes, all kinds of components of different chemical characters have to be handled. A full conversion always has to be assured. In Fig. 7, the conversion-temperature relation has been plotted for propane and propene. Also, the bestfit results according to the model are shown: the model describes the experiments quite well. The sensitivity of the propene oxidation to the reaction temperature is high, and therefore a high activation energy must be expected. Furthermore, it can be observed from this figure that defining a minimum temperature as that temperature where the reaction starts can give erroneous results. In this specific case, it would suggest that both components react equally well or that it is even easier to oxidize propane. In general, the behaviour of propane and propene is representative for the alkanes and alkenes, respec-

Table 3. The minimum reaction temperature, $T_{99}\left({ }^{\circ} \mathrm{C}\right)$, for $\tau_{0}=1 \mathrm{~s}$ and the activation energy, $E_{\text {act }}(\mathrm{kJ} / \mathrm{mol})$, for the different organic components and catalysts; for properties of the catalysts see Table 2

\begin{tabular}{|c|c|c|c|c|c|c|c|c|c|c|}
\hline \multirow[b]{2}{*}{ Component } & \multicolumn{2}{|c|}{ I. $\mathrm{Pd} / \gamma-\mathrm{Al}_{2} \mathrm{O}_{3}$} & \multicolumn{2}{|c|}{ II. $\mathrm{Pd} / \gamma-\mathrm{Al}_{2} \mathrm{O}_{3}$} & \multicolumn{2}{|c|}{ III. $\mathrm{PV} / \gamma-\mathrm{Al}_{2} \mathrm{O}_{3}$} & \multicolumn{2}{|c|}{ IV. $\mathrm{PL} / \mathrm{TiO}_{2}$} & \multicolumn{2}{|c|}{$\begin{array}{l}\text { V. } \mathrm{Cu}-\mathrm{Mn} / \\
\mathrm{Al}_{2} \mathrm{O}_{3}\end{array}$} \\
\hline & $E_{\mathrm{acl}}$ & $T_{99}$ & $E_{\mathrm{uct}}$ & $T_{99}$ & $E_{\mathrm{acl}}$ & $T_{99}$ & $E_{\mathrm{act}}$ & $T_{99}$ & $E_{\mathrm{uct}}$ & $T_{99}$ \\
\hline Methane & 75.2 & 513 & 72.3 & 355 & 88.6 & 647 & 104.4 & 645 & 82.9 & 489 \\
\hline Ethane & 60.9 & 473 & - & - & - & - & - & - & - & - \\
\hline Ethene & 72.9 & 297 & 56.5 & 242 & 88.7 & 136 & 107.2 & 133 & 51.2 & 259 \\
\hline Propane & 48.0 & 426 & 58.0 & 313 & 52.8 & $46 I$ & 37.4 & 495 & 39.3 & 361 \\
\hline Propene & 137.2 & 234 & 105.3 & 220 & 131.3 & 167 & 152.8 & 180 & 40.0 & 231 \\
\hline n-Butane & 52.1 & 405 & - & - & - & - & - & - & 35.8 & 327 \\
\hline l-Butene & 126.5 & 225 & - & - & - & - & - & - & 39.6 & 224 \\
\hline Isobutane & 44.1 & 430 & - & - & - & - & - & - & 37.1 & 305 \\
\hline Isobutene & 141.8 & 234 & - & - & - & - & - & - & 30.1 & 218 \\
\hline
\end{tabular}




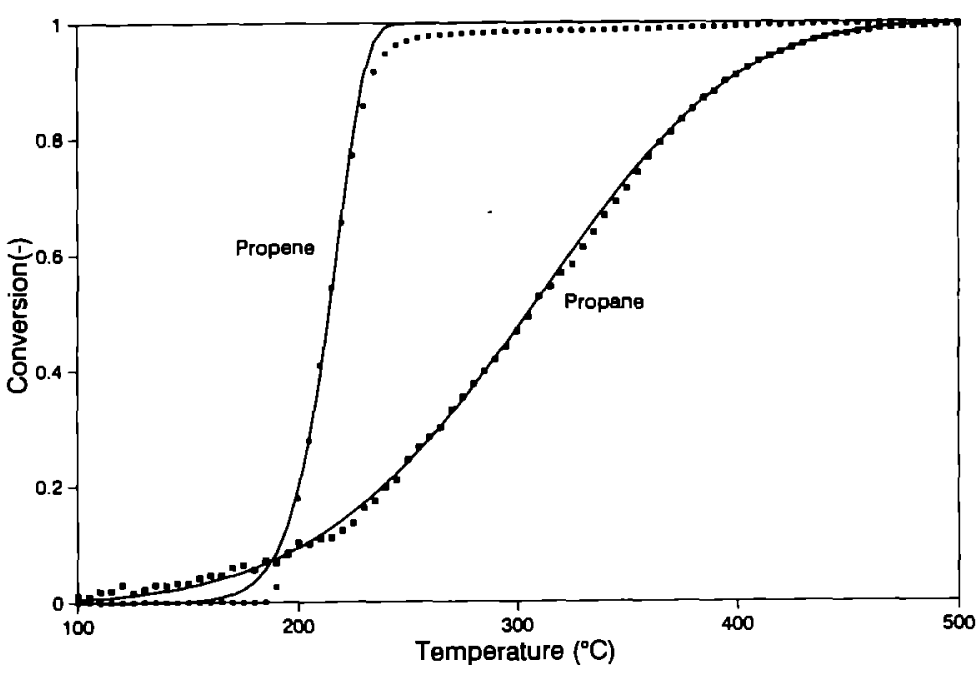

Fig. 7. Conversion profile as a function of the reaction temperature for propane and propene. The lines are calculated using the model. For kinetic parameters see Table 3; $C_{0}=0.085$ vol\%; $u_{g 0}=0.26 \mathrm{~m} / \mathrm{s} ; L=0.2 \mathrm{~m}$; Catalyst I, see Table 2 .

tively. This is supported by Fig. 8 where $T_{99}$ is plotted as a function of the number of $\mathrm{C}$ atoms in the compound for residence times between 0.4 and $1.6 \mathrm{~s}$. $T_{99}$ for alkanes is always higher than for the corresponding alkenes. Generally, increasing the number of $\mathrm{C}$ atoms is accompanied by a decrease in $T_{99}$. In Table 3, the activation energy and $T_{99}$ are given for the components studied. It is remarkable that the results for isobutane and isobutene are very close to those for propane and propene, respectively. This coincides with the observations of Hiam et al. (1968) and Schwartz et al. (1971).

\section{Multi-component mixtures}

The reaction rates of single organic components may be influenced by the presence of other components. Tichenor and Palazzolo (1987) studied the catalytic oxidation of mixtures containing up to seven different organic components. Depending on the nature of the components they found that individual reactions were inhibited, remained unchanged or in some cases were even enhanced. Hermia and Vigneron (1993) observed that the oxidation of $n$-hexane was positively influenced by toluene, whereas Gangwal et al. (1988) found a significant inhibition by benzene. The oxidation of benzene was not affected by $n$-hexane. Similar results were obtained by Barresi et al. (1992) and Mazzarino and Barresi (1993) for the deep oxidation of aromatic compounds on a Pt catalyst. For binary mixtures, Moro-oka et al. (1967) observed a decrease in the reaction rate of at least one of the components. Their results were explained by competitive adsorption; the inhibitive effect of different

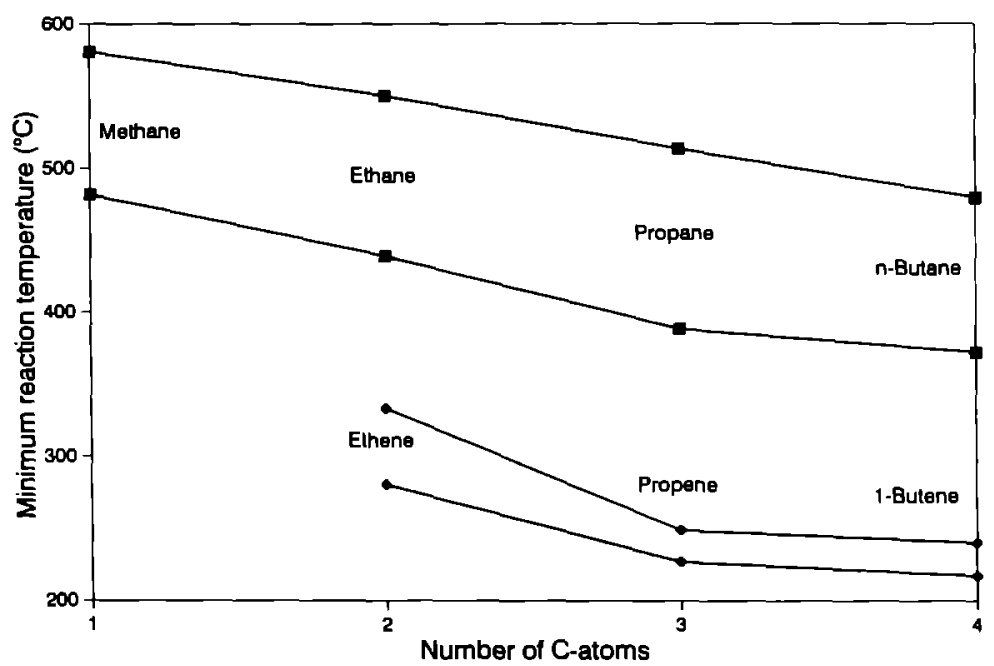

Fig. 8. Minimum reaction temperature as a function of the number of $\mathrm{C}$ atoms for alkanes and alkenes and for $\tau_{0}=0.4 \mathrm{~s}$ and $\tau_{0}=1.6 \mathrm{~s} . C_{0 . \mathrm{HC}}=1.2 \mathrm{~g} \mathrm{C} / \mathrm{m}^{3}$; Catalyst I, see Table 2 . 


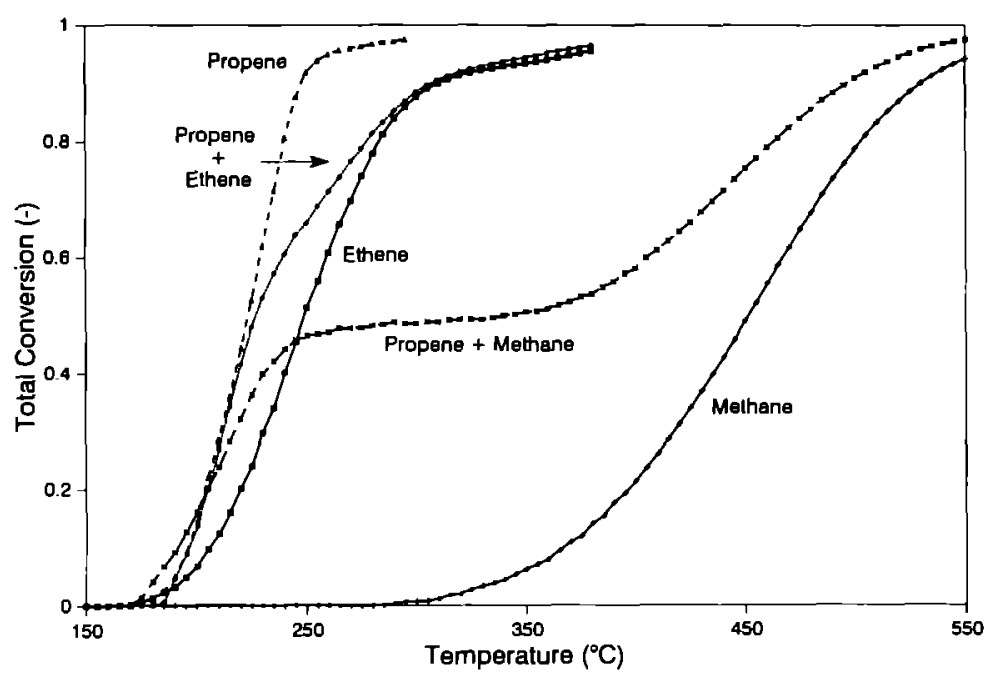

Fig. 9. Conversion profiles for single components and for mixtures as a function of the bed temperature. $L=0.10 \mathrm{~m} ; u_{g 0}=0.2 \mathrm{~m} / \mathrm{s} ; C_{0, \mathrm{HC} \text { toral }}=1-1.4 \mathrm{~g} \mathrm{C} / \mathrm{m}^{3}$; Catalyst $I$, see Table 2.

organic components was found to be in the order of their adsorption lengths on the catalysts used.

In Fig. 9, the conversion of several single components and mixtures are plotted as a function of the temperature. For a mixture of ethene/propene, as well as propene/methane, neither a positive nor negative significant mixture effect was observed. For components reacting in a completely different temperature range, see, e.g. a mixture of propene and methane, it is still possible to obtain the kinetic parameters of the individual reactions. If reactions take place in the same temperature range it is impossible to distinguish the kinetic parameters of single components.

\section{Influence of water}

The influence of water in the feed has been studied, because of a possible inhibition by water. Simon and
Vortmeyer (1978), studying the kinetics of the oxidation of ethane on a Pd catalyst, found a strong influence of water vapour on the reaction rate. Reaction rates were only constant at high water concentrations. Similar results were obtained by Mezaki and Watson (1966), Cullis et al. (1972) and Ribeiro et al. (1994) for the oxidation of methane and they were explained as follows: due to the formation of $\mathrm{Pd}(\mathrm{OH})_{2}$ on the $\mathrm{PdO}$ surface caused by water, the reaction of $\mathrm{CH}_{4}$ is effectively suppressed, because only the $\mathrm{PdO}$ phase is active. Or, in other words, $\mathrm{CH}_{4}$ has to compete with $\mathrm{H}_{2} \mathrm{O}$ for $\mathrm{PdO}$ surface sites. Brewer et al. (1994) concluded that the presence of water vapour severely inhibited the oxidation of methanol. Contrary to this, Germain and Peuch (1969) and Chang and Weng (1993) did not observe any inhibition effect of water vapour for the oxidation

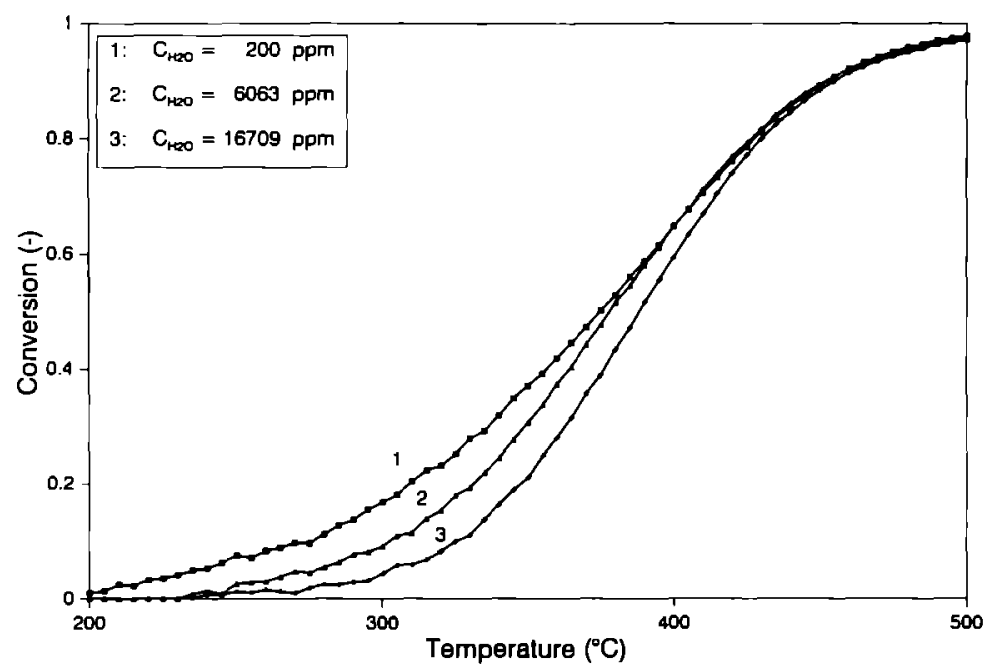

Fig. 10. Conversion profiles of propane as a function of the bed temperature for different inlet concentrations of water. $C_{0 . \text { propune }}=0.063 \mathrm{vol} \% ; u_{p 0}=0.19 \mathrm{~m} / \mathrm{s} ; L$ $=0.1 \mathrm{~m} ;$ Catalyst $\mathrm{I}$, see Table 2 . 
of benzene and toluene, respectively. The reaction mechanism is probably different for these aromatic compounds.

In Fig. 10, the conversion of propane is plotted as a function of the bed temperature for different inlet concentrations of water vapour. In general, the temperature at which the reaction starts increases with increasing water content in the feed. However, $T_{99}$ does hardly change: at high temperatures the conversion is almost independent of the water concentration. The presence of water results in an apparently higher activation energy; in particular, for the alkanes the change in $E_{\text {acl }}$ can be up to $30 \mathrm{~kJ} / \mathrm{mol}$. Now, if it is assumed that water adsorbs on the adsorbed oxygen, the following reaction rate expression can be derived; see Golodets (1983):

$$
R=\frac{k_{\mathrm{O}_{2}} k_{R} P_{\mathrm{O}_{1}} P_{\mathrm{HC}}}{k_{\mathrm{O}_{2}} P_{\mathrm{O}_{2}}\left(1+K_{\mathrm{H}_{2} \mathrm{O}} P_{\mathrm{H}_{\mathrm{O}} \mathrm{O}}\right)+v k_{R} P_{\mathrm{HC}}} .
$$

The oxygen partial pressure is constant and in a large excess. Furthermore, if $\nu k_{R} P_{\mathrm{HC}} \ll k_{\mathrm{O}_{2}} P_{\mathrm{O}_{2}}(1+$ $K_{\mathrm{H}_{2} \mathrm{O}} P_{\mathrm{H}_{2}}$ ) is assumed, eq. (5) reduces to:

$$
R=\frac{k_{R} P_{\mathrm{HC}}}{1+K_{\mathrm{H}_{2} \mathrm{O}} P_{\mathrm{H}_{2} \mathrm{O}}}
$$

Mezaki and Watson (1966), studying the influence of water vapour on the methane oxidation on a $\mathrm{Pd} /$ $\gamma-\mathrm{Al}_{2} \mathrm{O}_{3}$ catalyst, found, for the chemisorption constant of water $K_{\mathrm{H}_{2} \mathrm{O}, x} \exp \left(E_{\text {ads }} / R T\right)$, the following values: $K_{\mathrm{H}_{2} \mathrm{O}, x}=9.6 \times 10^{-7} \mathrm{~Pa}^{-1}$ and $E_{\text {ads }}=33.5 \mathrm{~kJ} /$ mol. For a satisfactory agreement between experiments and calculations $K_{\mathrm{H}_{2} \mathrm{O}} \infty$ had to be multiplied by a factor of ten. Similar attempts to explain the influence of water on the oxidation rates of alkenes with the aid of eq. (5) failed. The assumption of $v k_{R} P_{\mathrm{HC}} \ll k_{\mathrm{O}_{2}} P_{\mathrm{O}_{2}}\left(1+K_{\mathrm{H}_{2} \mathrm{O}} P_{\mathrm{H}_{2}}\right)$ probably is not valid for alkenes and eq. (4) should be used. For ethene, a small increase in $T_{99}$ was found after the addition of water. Surprisingly, the oxidation of propene was even enhanced by small amounts of water; see Fig. 11.

\section{Catalysts and support material}

Different catalysts and support materials were examined for the complete oxidation. As active material, noble metals were used as well as metal oxides. Generally, metal oxides are less active than noble metals. In practice, for complete catalytic combustion the use of noble metals is restricted to $\mathrm{Pt}$ and Pd. For the oxidation of alkenes and methane, the specific activity of $\mathrm{Pd}$ is larger than that of $\mathrm{Pt}$, while for the combustion of propane and higher alkanes, the activity of Pt is larger; see Prasad et al. (1984) and Zwinkels et al. (1993).

In Figs 12 and 13, the conversion of methane and propene is plotted as a function of the temperature for different catalyst systems; see Table 2 for the properties for the catalysts. The conversions of methane and propene obtained on $\alpha-\mathrm{Al}_{2} \mathrm{O}_{3}$ and $\gamma-\mathrm{Al}_{2} \mathrm{O}_{3}$ were only slightly higher than in an empty reactor and hence the activity of these support materials can be neglected. These results agree with observations of Cullis and Willatt (1983), albeit the activity of a catalyst can be strongly influenced by changing the support material; see Anderson et al. (1961) and Niwa et al. (1983).

Increasing the $\mathrm{Pd}$ content results in a higher activity for both methane and propene; see Figs 12 and 13. Unexpectedly, both Pt catalysts gave nearly the same conversion-temperature relations despite the Pt-loading difference of almost a factor of two. Cullis and Willatt (1983) found that Pt exhibits a high activity if supported on $\gamma-\mathrm{Al}_{2} \mathrm{O}_{3}$. When using $\mathrm{TiO}_{2}$ as support, a less active catalyst was obtained. Probably the lower specific activity of Catalyst IV compared to Catalyst III is compensated for by a higher Pt-loading such that the overall activity remains nearly the same. Regretfully, it was not

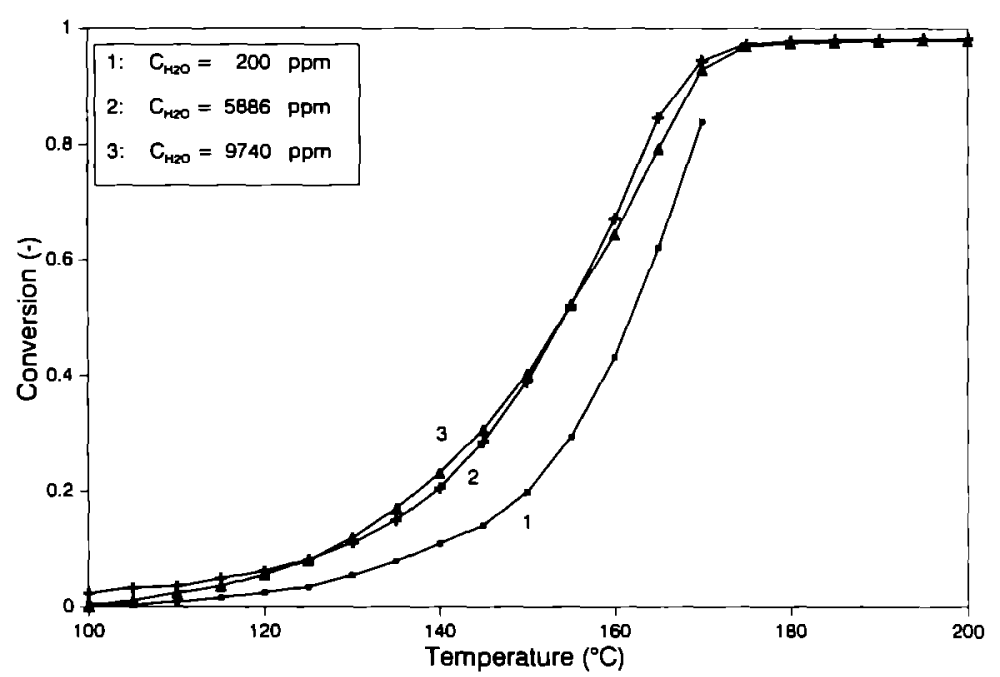

Fig. 11. Conversion profiles of propene as a function of the bed temperature for different inlet concentrations of water. $C_{0 . \text { propenc }}=0.063 \mathrm{vol} \% ; u_{k 0}=0.19 \mathrm{~m} / \mathrm{s} ; L$ $=0.1 \mathrm{~m}$; Catalyst IV, see Table 2 . 


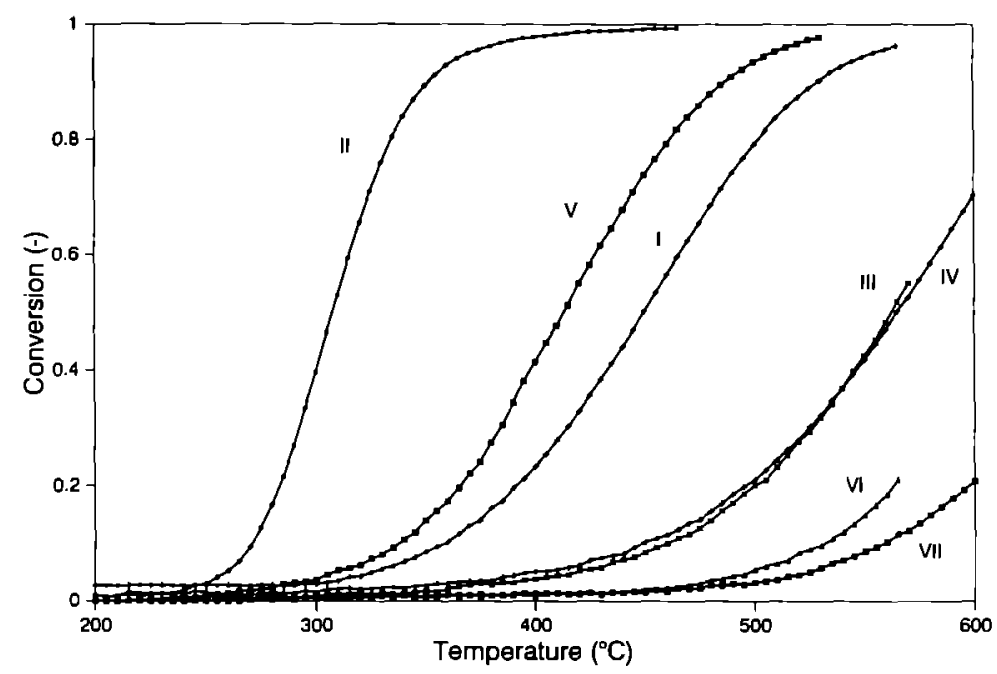

Fig. 12. Conversion profiles of methane as a function of temperature for different catalysi materials. $C_{0 \text {,methane }}=0.22 \mathrm{vol} \% ; u_{g 0}=0.19 \mathrm{~m} / \mathrm{s} ; L=0.1 \mathrm{~m}$; for properties of catalysts see Table 2.

possible to investigate the $\mathrm{Pt}$ dispersion on the support in this work. According to Spivey (1987), among the metal oxides $\mathrm{MnO}_{2}-\mathrm{CuO}$ is a suitable deep oxidation catalyst. For the methane oxidation, it was found in this work that the activity of $\mathrm{MnO}_{2}-$ $\mathrm{CuO}$ was in between those of the two Pd catalysts. The Pt catalysts showed the lowest activity. Hicks et al. (1990a,b) concluded that the activity of supported Pt and Pd catalysts is very structure sensitive; this was explained by the differences in the reactivity of the adsorbed oxygen on the different forms of the metal surfaces. Anderson et al. (1961) studied the activity of different catalysts on the same $\mathrm{Al}_{2} \mathrm{O}_{3}$ support material and found the following order of reactivity for the oxidation of methane: $\mathrm{Pt}>\mathrm{Pd}>$ $\mathrm{Mn}>\mathrm{Cu}$.

In the experiments in this work, both Pt catalysts showed the same high activity for the complete oxidation of propene; Pd was less active for the combustion of alkenes, which is contradictory to most studies in the literature; see, e.g. Moro-oka et al. (1967) and Shinjoh et al. (1989). The oxidation of propene on the $\mathrm{MnO}_{2}-\mathrm{CuO}$ catalyst already started at a low temperature, but $T_{99}$ was nearly the same as found for the Pd catalysts.

In Table 3, the activation energy $E_{\mathrm{act}}$ and the minimum temperature for complete conversion $T_{99}$ are given for the different catalyst systems. On the noble metals, a high activation energy is obtained for the combustion of alkenes; on the $\mathrm{MnO}_{2}-\mathrm{CuO}$ catalyst, the activation energies are nearly the same for alkenes as for alkanes with the same chain length. For the catalysts and organic compounds studied in this work, the best catalyst was the Pd catalyst (see Table 2, Catalyst II) because for this catalyst all components are completely converted below $400^{\circ} \mathrm{C}$.

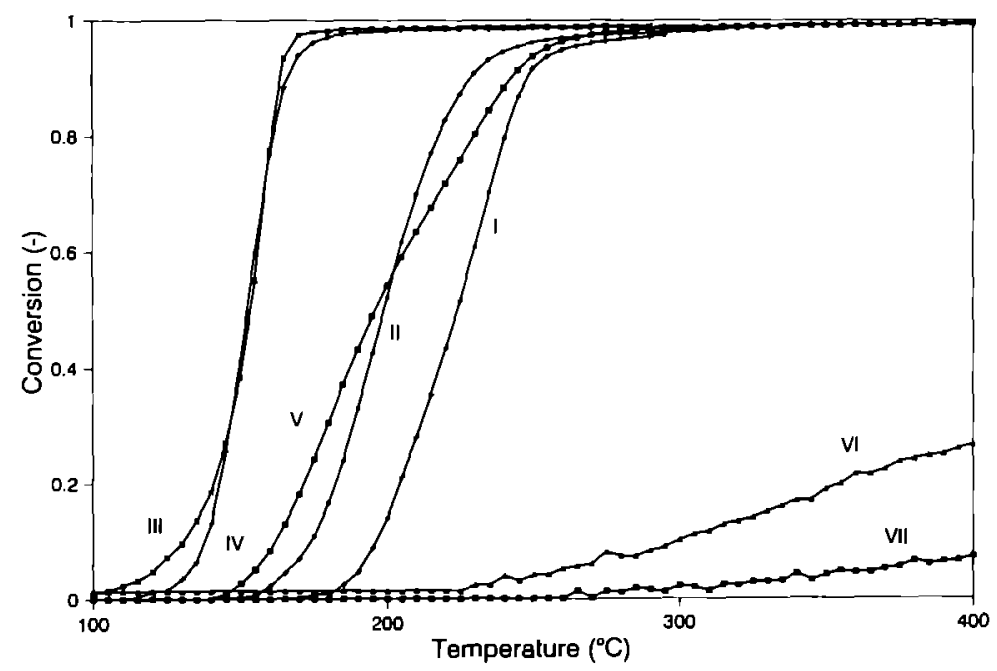

Fig. 13. Conversion profiles of propene as a function of temperature different catalyst materials. $C_{0, \text { propenc }}=0.07 \mathrm{vol} \% ; u_{k 0}=0.19 \mathrm{~m} / \mathrm{s} ; L=0.1 \mathrm{~m} ;$ for properties of catalysts see Table 2. 


\section{CONCLUSIONS}

A fast method was presented for the determination of the minimum reaction temperature to achieve high conversions for the catalytic oxidation of hydrocarbons. It is a quick, dynamic method, but its accuracy is not overwhelming. Following the hydrocarbon concentration in the reactor outlet as a function of the bed temperature gives sufficiently accurate information. This is in contrast to the $\mathrm{CO}_{2}$ temperature relations, which gave erroneous results caused by either adsorption of $\mathrm{CO}_{2}$ or formation of an intermediate product.

The influence of the residence time was studied by changing both the reactor length and the gas velocity, and, as expected, increasing the residence time decreases $T_{99}$. The oxidation of different organic components was studied: in general, the alkenes are easier to oxidize than the alkanes. Increasing the number of $\mathrm{C}$ atoms reduces the minimum reaction temperature. For several organic components in the feed, a significant mixture effect was not observed. However, if water (one of the reaction products) was added to the feed, the combustion of the alkanes was inhibited, particularly at low temperatures. On the contrary, in the case of propene, even a small enhancement of the oxidation reaction was found. The performance of different catalysts and support materials was tested. The activity of the support material was negligible. For the oxidation of the alkenes, Pt was the most active. Alkanes were easier to oxidize on Pd and the activity of $\mathrm{Pt}$ for these components was low. The experiments were fitted to a reactor model and in this way numerical values of the kinetic parameters could be obtained. Recalculating the experimental profiles with the best-fit values showed a reasonable agreement.

Acknowledgements - These investigations were supported by the Netherlands' Foundation for Chemical Research (SON) with financial aid from the Netherlands' Technology Foundation and DSM. Hüls AG is gratefully acknowledged for supplying part of the catalyst materials. The authors wish to thank J. H. Alferink, M. Idsinga, S. van Triest, P. Beekman and S.P.B. Lemmers for doing part of the experimental work, and G. H. Banis, F. ter Borg. K. van Bree, O.D. Veehof and A.H. Pleiter for technical assistance.

\section{NOTATION}

C concentration, $\mathrm{mol} / \mathrm{m}^{3}$

$E_{\text {act }}$ activation energy, $\mathrm{kJ} / \mathrm{mol}$

$E_{\text {ads }} \quad$ adsorption energy, $\mathrm{kJ} / \mathrm{mol}$

$k_{\mathrm{O}_{2}}$ rate constant of oxygen adsorption, mol/ $\mathrm{Pa} \mathrm{m}^{3} \mathrm{~s}$

$k_{r} \quad$ reaction rate constant, $\mathrm{mol} / \mathrm{Pa} \mathrm{\textrm {m } ^ { 3 } \mathrm { s }}$

$k_{\mathrm{x}} \quad$ pre-exponential factor, $\mathrm{mol} / \mathrm{Pa} \mathrm{m}^{3} \mathrm{~s}$

$K \quad$ adsorption constant, $\mathrm{Pa}^{-1}$

$K \quad$ reactor length, $\mathrm{m}$

$P \quad$ (partial) pressure, $\mathrm{Pa}$

$R \quad$ gas constant, $\mathrm{kJ} / \mathrm{mol} \mathrm{K}$

$R_{j} \quad$ reaction rate of component $j, \mathrm{~mol} / \mathrm{m}^{3} \mathrm{~s}$

\author{
$T \quad$ temperature, $\mathrm{K}$ \\ $\bar{T} \quad$ mean temperature, $\mathrm{K}$ \\ $T_{99}$ minimum reaction temperature for $99 \%$ \\ conversion, $\mathrm{K}$ \\ ug superficial gas velocity, $\mathrm{m} / \mathrm{s}$ \\ $z \quad$ axial position in reactor, $m$
}

\section{Greek letters}

$v \quad$ stoichiometric ratio

$\tau \quad$ residence time, $s$

$\xi$ conversion

\section{Subscripts and superscripts}

g gas

HC hydrocarbon

j component $j$

$r$ reaction

0 reference conditions ( 1 bar and $298 \mathrm{~K}$ )

\section{REFERENCES}

Agarwal, S. K. and Spivey, J. J., 1992, Deep oxidation of hydrocarbons. Appl. Cal. A: General 81, 239-255.

Anderson. R. B., Stein, K. C., Feenan, J. J. and Hofer, L. J. E., 1961, Catalytic oxidation of methane. Ind. Engng Chem. 53, 809-812.

Baldwin , T. R. and Burch, R., 1990a, Catalytic combustion of methane over suppored palladium catalysts I. Alumina supported catalysts. Appl. Cotal. 66, 337-358.

Baldwin, T. R. and Burch, R., 1990b. Catalytic combustion of methane over supported palladium catalysts II. Support and possible morphological effects. Appl. Catal. 66, 359-381.

Barresi, A. A., Mazzarino, I. and Baldi, G., 1992, Gas phase complete oxidation of aromatic hydrocarbon mixtures. Can. J. Chem. Engng 70, 286-293.

Boreskov, G. K., 1966, Forms of oxygen bonds on the surface of oxidation calalysts. Disc. Faraday Soc. 41, 263-276.

Brewer, T. F., Abraham, M. A. and Silver, R. G., 1994, Mixture effects and methanol oxidation kinetics over a palladium monolith catalyst. Ind. Engng Chem. Res. 33, 526-533.

Briot, P. and Primet, M., 1991, Catalytic oxidation of methane over palladium supported on alumina. Effect of aging under reactants. Appl. Catal. 68, 301-314.

Chang, C. C. and Weng, H. S., 1993, Deep oxidation of toluene on perovskile catalyst. Ind. Engng Chem. Res. 32, 2930-2933.

Chen, N. H. and Aris, R., 1992, Determination of Arrhenius constants by linear and nonlinear fitting. A.I.Ch.E. J. 38, 626-628.

Cullis, C. F. and Willatt, B. M., 1983, Oxidation of methane over supported precious metal calalysts. J. Caral. 83, 267-285.

Cullis, C. F., Nevell, T. G. and Trimm, D. L., 1972, Role of the catalyst suppor in the oxidation of methane over palladium. J. Chem. Soc. Faraday Trans. I 68, $1406-1412$.

Frusteri, F., Arena, F., Parmaliana, A., Mondello, N. and Giordano, N., 1993, On the reduclion of $\mathrm{Pd}^{2+}$ forms in $\mathrm{Pd} / \gamma-\mathrm{Al}_{2} \mathrm{O}_{3}$ catalysts. React. Kinet. Catal. Lett. 51, $331-342$.

Gangwal, S. K., Mullins, M. E., Spivey, J. J., Caffrey, P. R. and Tichenor, B. A., 1988, Kinetics and selectivity of deep catalytic oxidation of $n$-hexane and benzene. Appl. Cat. 36, 23I-247.

Garbowski, E., Feumi-Jantou, C., Mouaddib, N. and Primet, M., 1994, Catalytic combustion of methane over palladium supported on alumina catalysts: Evidence for reconstruction of particles. Appl. Catal. A: General 109. 277-291. 
Germain, J. E. and Peuch, J. C., 1969, Cinétique de l'oxidation catalytique du benzène sur oxydes de vanadium-molybdène. III. Sélectivité, activité et composition du catalyseur. Bull. Soc. Chim. France 6, 1844-1851.

Golodets, G. I., 1983, Heterogeneous Caralytic Reacrions involving Molecular Oxygen. Studies in Surface Science and Caralysis, Vol. 15. Elsevier, Amsterdam.

Hermia, J. and Vigneron, S., 1993, Catalytic incineration for odour abatement and VOC destruction. Catalysis Today 17, 349-358.

Hiam, L., Wise, H. and Chaikin, S., Catalytic oxidation of hydrocarbons on platinum. J. Catal. 9-10, 272-276

Hicks, R. F., Qi, H., Young, M. L. and Lee, R. G., 1990a, Effect of catalyst structure on methane oxidation over palladium on alumina. J. Catal. 122, 280-294.

Hicks, R. F., Qi, H., Young, M. L. and Lee, R. G., 1990b, Structure sensitivity of methane oxidation over platinum and palladium. J. Catal. 122, 295-306.

Kuznetsoya, L. L., Paukshtis, E. A., Shkurina, G. P., Shkrabina, R. A., Koryaabkina, N. A., Arenderskii, D. A., Barannik, G. B. and Ismagilov, Z. R., 1993, Chromium catalysts for hydrocarbon destruction. Catalysis Today 17, 209-216.

Mazzarino, I. and Barresi, A. A., 1993, Catalytic combustion of VOC mixtures in a monolithic reactor. Caralysis Today 17, 335-348

Mezaki, R. and Watson, C. C., 1966, Catalytic oxidation of methane. IEC Proc. Des. Dev. 5, 62-65.

Moro-oka, Y., Morikawa, Y. and Ozaki, A., 1967, Regularity in the catalytic properties of metal oxides in hydrocarbon oxidation. J. Catal. 7, 23-32.

Mulcahy, F. M., Kozminski, K. D., Slike, J. M., Ciccone, F, Scierka, S. J. Eberhardt, M. A., Houalla, M. and Hercules, D. M., 1993, Chemisorption of $\mathrm{CO}_{2}$ on alumina supported catalysts. J. Catal. 139, 688-690.

Najbar, M., Baranska, M. and Jura, W. ,1993, Low temperature oxidation of light hydrocarbons over silica supported noble metal catalysts. Calalysis Today 17 , 201-208.

Niwa, M., Awano, K. and Murakami, Y., 1983, Activity of supported platinum catalysts for methane oxidation. Appl. Catal . 7, 317-325.
Noordally, E., Richmond, J. R. and Tahir, S. F, 1993, Destruction of volatile organic compounds by catalytic oxidation. Calalysis Today 17, 359-366.

Prasad, R., Kennedy, L. A. and Ruckenstein, E., 1984, Catalytic combustion. Catal. Rev-Sci. Engng 26, I-58.

Press, W. H., Flannery, B. P., Teukolsky, S. A. and Vetterling, W. T., 1989, Numerical Recipes in Pascal. The Art of Scientific Computing. Cambridge University Press, Cambridge.

Ribeiro, F. H., Chow, M. and Dalla Betta, R. A., 1994, Kinetics of the complete oxidation of methane over supported palladium catalysts. J. Catal. 146, 537-544.

Schwartz, A., Holbrook, L. L. and Wise, H., 1971, Catalytic oxidation studies with platinum and palladium. J. Caral. 21, 199-207.

Shinjoh, H., Muraki, H. and Fujitani, Y., 1989, Periodic operation effects in propane and propylene oxidation over noble metal catalysts. Appl. Caral. 49, 195-204.

Simon, B. and Vormeyer, D., 1978, Measured and calculated migrating speeds of reaction zones in a fixed bed reactor, a quantitative comparison. Chem. Engng Sci. 33, $109-1$ I 4.

Spivey, J. J., 1987, Complete catalytic oxidation of volatile organics. Ind. Engng Chem. Res. 26, 2165-2180.

Taskina, S. Yu, Kinichenko, O. A. and Chermashentseva, G. $\mathrm{K}$, 1993, Oxidation of methane, butane and carbon monoxide on $\mathrm{Al}-\mathrm{Fe}$ oxide catalysts. React. Kinet. Catal. Lett. 49, 235-240.

Tichenor, B. A. and Palazzolo, M. A., 1987. Destruction of volatile organic compounds via calalytic incineration. Environ. Prog. 6, 172-176.

Wentworth, W. E., 1965a, Rigorous least squares adjustment application to some non-linear equations I. J. Chem. Education 42, 96-103.

Wentworth, W. E., 1965b, Rigorous least squares adjustment application to some non-linear equations II. $J$. Chem. Education 42, 162-167.

Zwinkels, M. F. M., Jaras, S. G. and Menon, P. G., 1993, Catalytic materials for high-temperature combustion. Catal. Rev.-Sci. Engng 35, 319-358. 